\section{Regards sur l'économie allemande}

Bulletin économique du CIRAC

$118-119 \mid 2015$

Varia

\title{
Économie numérique : peu de destruction d'emplois
}

Isabelle Bourgeois

\section{(2) OpenEdition}

Édition électronique

URL : http://journals.openedition.org/rea/4900

DOI : $10.4000 /$ rea. 4900

ISSN : 1965-0787

Éditeur

CIRAC

\section{Édition imprimée}

Date de publication : 31 décembre 2015

Pagination : 38-39

ISSN : 1156-8992

\section{Référence électronique}

Isabelle Bourgeois, "Économie numérique : peu de destruction d'emplois ", Regards sur l'économie

allemande [En ligne], 118-119 | décembre 2015, mis en ligne le 31 décembre 2017, consulté le 15 septembre 2020. URL : http://journals.openedition.org/rea/4900

Ce document a été généré automatiquement le 15 septembre 2020.

(c) CIRAC 


\title{
Économie numérique : peu de destruction d'emplois
}

\author{
Isabelle Bourgeois
}

Personne n'est irremplaçable ? Cette affirmation qui ne vaut guère déjà en Allemagne où les salariés sont communément considérés comme des personnes ressources, et leurs compétences donc comme uniques, vaudra encore moins à l'ère du numérique. Il n'y a pas à craindre que les robots viennent remplacer les humains - du moins presque, à en croire une étude que vient de publier l'institut IAB de Nuremberg (IAB-Kurzbericht, 24/2015).

\section{$0,4 \%$ seulement des actifs pourraient voir leur emploi détruit}

2 En réponse à une étude publiée en 2013 aux Etats-Unis par les économistes Frey et Osborne, et qui parvient à la conclusion qu'au cours des deux prochaines décennies, près de la moitié des emplois américains seront remplacés par des machines numérisées, Katharina Dengler et Britta Matthes, chercheurs à l'IAB, ont analysé pour la première fois l'impact que la robotisation accélérée pourrait avoir sur la structure des emplois en Allemagne. Certes, la numérisation va profondément modifier l'emploi et les types de fonctions. Mais seuls $0,4 \%$ des actifs occupant un emploi soumis à cotisations sociales devraient voir leur emploi détruit par l'automatisation principalement dans l'industrie (production et services liés). Les services à la personne sont à l'évidence peu concernés, aucun robot n'étant en mesure de remplacer l'humain. Cela vaut encore plus pour le secteur culturel et créatif. Plus généralement, plus les qualifications requises sont élevées et plus fonctions sont complexes et incluent des responsabilités, moins le risque de substitution existe. 


\section{Comment prévenir ce risque?}

3 Néanmoins, $15 \%$ des actifs occupant un emploi soumis à cotisations sociales pourraient voir automatisée une grande partie (70\%) de leurs tâches. 45 \% des actifs occupant un tel emploi exercent des métiers où le risque de substitution peut être considéré comme moyen : entre 30 et $70 \%$ des tâches pourraient être accomplies par un ordinateur. $40 \%$ ont un métier où moins de $30 \%$ seulement des tâches sont numérisables (dont $8 \%$ où aucune substitution n'est possible). Ces calculs sont des maxima arithmétiques, purement théoriques, qui ne tiennent pas compte de l'évolution de la réglementation ni des calculs de rentabilité que pourraient faire les entreprises. Ils ont pour principal mérite de démontrer que, à l'ère du numérique non plus, rien ne permet d'affirmer que l'automatisation détruit massivement l'emploi. Et de rappeler qu'il convient au contraire de considérer très précisément le type de tâches et fonctions, elles substituables, pour que, riche de l'expérience historique des perpétuelles mutations de l'emploi et surtout de la genèse de nouveaux types d'emplois qu'induit toute nouvelle technologie, il soit possible de prévenir le risque de destruction des plus exposés.

\section{Par un effort accru de formation initiale et continue}

Comment relever le défi de l'économie du futur? «Pour toujours maintenir le savoir et le savoir-faire au niveau des dernières évolutions technologiques, la formation professionnelle initiale et continue jouera un rôle de plus en plus important - pas seulement pour les moins qualifiés, mais au moins tout autant pour les plus qualifiés». Cette formation mettra un accent plus prononcé encore sur l'adaptabilité à toute donne nouvelle - objectif premier du lifelong learning. C'est là une approche typique pour l'Allemagne: la meilleure réponse à toute mutation et à ses répercussions sur la structure de l'emploi a toujours consisté et consiste plus que jamais dans un effort renforcé de formation professionnelle. Le titre de cette étude de l'IAB pourrait ainsi bien devenir réalité : "L'homme ne peut [ndT: et même ne saurait] être totalement remplacé dans presque aucun métier».

\section{INDEX}

Mots-clés : numérique, emploi, formation 